\title{
PEMASANGAN PERANGKAT PENGUAT DAYA GSM DI JALUR MENUJU AIR TERJUN SEGENTER LOMBOK BARAT
}

\author{
Installing A GSM Repeater on the Segenter Waterfall Path, \\ Lombok Barat
}

\author{
Budi Irmawati ${ }^{[1]}$, Cahyo Mustiko OM${ }^{[2]}$, Wirararama Wedashwara ${ }^{[1]}$, \\ Ahmad Zafrullah $^{[1]}$, Ramaditia Dwiyansaputra ${ }^{[1]}$, Ario Yudo Husodo ${ }^{[1]}$ \\ ${ }^{[1]}$ Dept of Informatics Engineering, Mataram University \\ ${ }^{[2]}$ Dept of Electrical Engineering, Mataram University \\ Jl. Majapahit 62, Mataram, Lombok NTB, INDONESIA \\ Email: \{budi-i, cahyo.muvianto, wirarama, zaf,rama\}@unram.ac.id, ario@ti.ftunram.ac.id
}

\begin{abstract}
Tahura Nuraksa berada di kawasan Taman Hutan Raya yang terletak di dusun Kumbi, desa Pakuan, Lombok Barat. Tahura Nuraksa sangat berpotensi untuk dikelola menjadi salah satu tujuan wisata di Lombok. Ia memiliki air terjun, goa, pura, danau, hutan, dan juga camping ground. Camping ground ini sering digunakan untuk kegiatan outbond dan perkemahan. Tahura juga memiliki area memanah, flying fox, dan kolam renang anak-anak. Salah satu spot yang menarik di kawasan tersebut adalah air terjun Segenter. Namun area air terjun tersebut merupakan area blank spot sehingga tidak dapat melakukan komunikasi dari dan ke area lain. Di lain pihak, untuk wisatawan sangat membutuhkan akses internet terutama untuk berkomunikasi dan update status. Di era digital saat ini, internet merupakan fasilitas utama bagi wisatawan.

Kegiatan pengabdian ini memasang sebuah penguat sinyal GSM pada jalur menuju air terjun tersebut. Dengan adanya penguat ini, komunikasi di area menuju air terjun telah dapat dilakukan menggunakan beberapa provider GSM. Namun demikian, permasalahan yang belum berhasil ditangani saat ini adalah kelemahan sinyal ketika cuaca mendung karena suply energi diperoleh dari tenaga matahari.
\end{abstract}

Keywords: Air terjun Segenter, Penguat GSM, Tahura Nuraksa, Wisata edukasi, Wisata kampung

\section{Pendahuluan}

TAHURA ${ }^{1}$ NURAKSA adalah salah satu taman hutan raya yang berada di propinsi NTB. Tahura ini sangat berpotensi untuk dikelola menjadi salah satu tujuan wisata di Lombok. Ia memiliki air terjun, goa, pura, danau, hutan, dan juga camping ground. Camping ground ini sering digunakan untuk kegiatan outbond dan perkemahan.

Saat ini Tahura Nuraksa juga sedang berproses untuk mewujudkan konsep wisata terpadu yang mengemas pemandangan alam dan kegiatan masyarakat di suatu wilayah sebagai obyek yang dijual. Dalam pengembangan ini, Balai Tahura Nuraksa memberdayakan pemuda-pemuda Desa Pakuan untuk mengelola kawasan wisata

\footnotetext{
${ }^{1}$ TAHURA adalah singkatan dari Taman Hutan Raya, yaitu daerah konservasi alam bagi flora dan fauna, baik yang berasal dari wilayah tersebut maupun dari wilayah lain.
} 
tersebut. Tujuan dari pengelolaan bersama ini agar rasa memiliki terhadap kawasan ini cukup tinggi sehingga tidak terjadi eksploitasi berlebihan terhadap wilayah hutan. Selain itu, untuk menarik minat wisatawan, diperlukan kemampuan promosi di sosial media. Promosi ini akan dilakukan oleh pemuda-pemuda desa Pakuan sebagai mitra dari Balai Tahura Nuraksa.

Namun demikian, saat ini, akses internet hanya dapat dilakukan dari area di sekitar kantor Balai Tahura Nuraksa karena ada satu BTS yang berada pada jarak 50 meter. Untuk area di sekitar air terjun, akses internet belum dapat dilakukan karena terlalu jauh dari BTS tersebut. Air terjun Segenter berada 2 km di utara kantor Balai Tahura Nuraksa.

Untuk mendukung program Balai Tahura Nuraksa, Program Studi Teknik Informatika Universitas Mataram melakukan kegiatan pengabdian msyarakat yang dikemas dalam dua bagian. Bagian pertama adalah berbagi pengetahuan untuk mempromosikan area wisata ini melalui media sosial. Bagian kedua adalah membangun sebuah penguat GSM agar jaringan internet dapat menjangkau area menuju air terjun. Pemilihan dukungan dalam hal ini karena: (1) Manusia tidak lepas dari akses ke sosial media sehingga fasilitas untuk selalu terhubung ke dunia maya menjadi salah satu daya tarik bagi wisatawan. (2) Koordinasi antara area kantor Balai Tahura dan area menuju pos air terjun akan dapat dilakukan jika jaringan nirkabel tersedia.

\section{Tinjauan Pustaka}

\subsection{Kegiatan Sejenis}

Pemasangan penguat GSM telah dilakukan di beberapa daerah wisata seperti di Desa Wisata Cibuntu-Kuningan [1]. Tujuannya adalah memperkuat sinyal seluler di daerah yang belum memiliki BTS. Penguat GSM juga dipasang di Desa Klapayan Kabupaten Bangkalan [2]. Tujuan pemasangan penguat ini untuk menghindari gangguan ketika UNBK karena daya tangkap sinyal yang lemah.

\subsection{Tahura Nuraksa}

Tahura Nuraksa berada di tiga desa. Dua desa di Lombok Barat, dan satu desa di Lombok Tengah, tepatnya di desa Pakuan dan Lembah Sempaga, Narmada, Kabupaten Lombok Barat, dan desa Karang Sidemen, Kabupaten Lombok Tengah. Luas wilayah Tahura Nuraksa sekitar 3.155 hektar dengan pintu masuknya berada di Dusun Kumbi, Desa Pakuan. Tahura Nuraksa memiliki tingkat kelembaban sekitar 60\% hingga 100\% dengan curah hujan antara 2.250 hingga $3.750 \mathrm{~mm}$ dengan kemiringan antara $5 \%$ hingga 40\%. Ia berada di ketinggian \pm 225 meter hingga \pm 684 meter di atas permukaan laut [3].

Tahura Nuraksa terdiri dari beberapa kawasan wisata yaitu Air Terjun Segenter, Goa Pengkoak, Kali Palang, dan Kumbi. Tahura Nuraksa saat ini menjadi jalur alternatif baru menuju puncak Rinjani yang dapat diakses melalui Goa Pengkoak. Oleh sebab itu, Tahura Nuraksa akan menjadi salah satu pintu gerbang tujuan wisata utama Lombok. Gambar 1 adalah peta kawasan Tahura Nuraksa. Peta ini menunjukkan letak obyek-obyek wisata yang ada di area tersebut.

\subsection{Penguat GSM}

Penguat sinyal GSM adalah suatu alat yang menerima sinyal GSM dari sebuah Base Transceiver Station (BTS) terdekat kemudian memancarkannya kembali ke area di sekitarnya dengan radius tertentu sesuai dengan kekuatannya. Penguat ini banyak dipasang pada area-area, di mana sinyal GSM tidak dapat diterima oleh perangkat bergerak akibat letaknya yang terlalu jauh dari BTS [4], banyak user yang menggunakan [5], atau karena kondisi geografis sehingga sinyal dari BTS terhalang oleh dataran yang lebih tinggi atau bangunan [6].

Liz dkk. [4] menyampaikan bahwa kekuatan sinyal akan berkurang sebanding dengan jarak penerima dari radio pemancarnya. Akibatnya, area yang dijangkau tidak sesuai dengan yang direncanakan dan melemah bahkan tidak dapat menangkap sinyal sama sekali. Pada kondisi seperti ini, peran rangkaian penguat menjadi salah satu harapan bagi masyarakat yang berada di area tersebut. Oleh sebab itu mereka melakukan survei terhadap berbagai rancangan penguat sebagai referensi untuk menentukan jenis penguat yang akan digunakan berdasarkan kondisi masing-masing.

Sementara itu Berkay dkk. [6] melakukan beberapa percobaan pada penguat indoor dan outdoor. Mereka menunjukkan bahwa penguat berhasil memperluas jangkauan area dan menunjukkan bahwa penguat yang diusulkan memiliki unjuk kerja yang lebih baik dari penguat sinyal tunggal lainnya. Di sisi lain, Aliyu dkk. [5] 


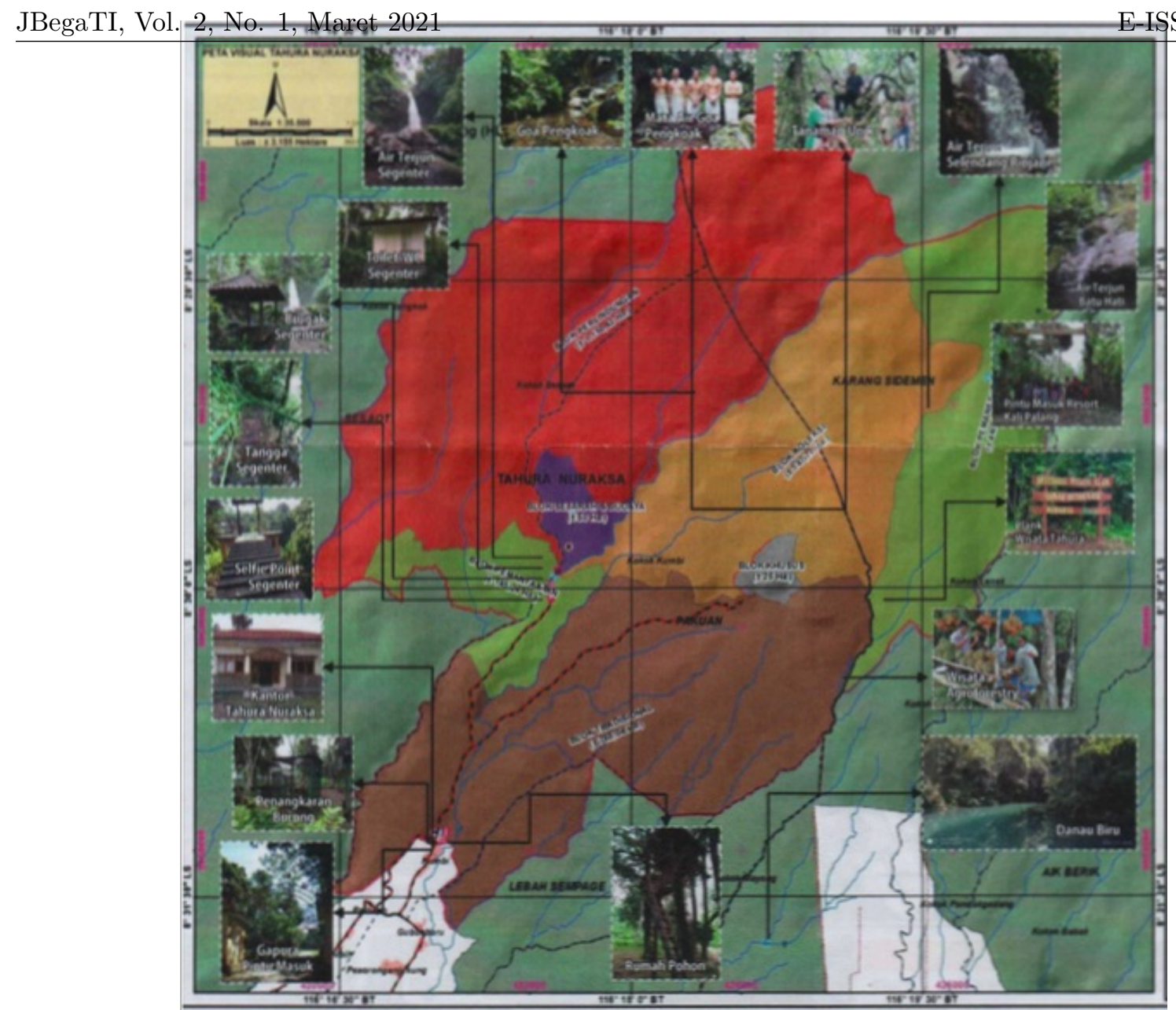

Gambar 1. Peta Tahura Nuraksa yang berada di tiga desa disertai dengan beberapa obyek wisata di kawasan tersebut [3].

memilih untuk melibatkan algoritma Bat dan Jaringan Syaraf Tiruan untuk mengoptimalkan penguatnya. Mereka mendapat penguatan sebesar $73.59 \%$ pada jaringan $2 \mathrm{G}$ dan $72.06 \%$ pada jaringan 3G.

Penguat biasanya dipasang pada sebuah tower di area yang cukup tinggi sehingga dapat menangkap sinyal GSM dari BTS terdekat. Penguat ini terdiri dari sebuah antena penerima satu arah, antena pemancar omni ke segala arah, rangkaian penguat, dan sumber daya. Sumber daya ini dapat berupa baterai yang disuplay dari sebuah sel surya, atau langsung dari catu daya dari PLN.

\section{Metode Pengabdian Masyarakat}

\subsection{Analisa Situasional}

Analisa ini dilaksanakan dalam beberapa tahap berupa survei sebelum proposal diajukan, komunikasi dengan pengelola Tahura Nuraksa, koordinasi tim untuk merencanakan pembelian peralatan yang akan dipasang, menentukan waktu pelaksanaan, dan kunjungan kembali untuk melihat kondisi peralatan setelah dipasang.

Kegiatan survei yang pertama dilaksanakan sebelum menyusun proposal ini adalah untuk mengetahui permasalahan di Tahura Nuraksa. Survei dilakukan dengan mewawancarai warga di sekitar kawasan ini dan kunjungan ke air terjun Segenter.

Sebenarnya banyak permasalahan yang dapat dicatat di kawasan tersebut. Di antaranya karena masyarakat memiliki hak guna lahan di area yang dekat dengan kampung. Pada area tersebut, banyak rakyat yang menanam pisang yang selanjutnya mereka jual untuk kebutuhan sehari-hari. Permasalahannya adalah mereka tidak menyelingi tanaman pisang dengan tanaman keras sehingga fungsi kawasan tahura sebagai kawasan konservasi 
akan berkurang. Perubahan fungsi tidak resmi ini harus segera ditangani agar kawasan hutan yang berubah menjadi perkebunan tidak semakin luas. Permasalahan kedua adalah keterbatasan akses internet seperti yang telah dijelaskan pada Bagian Pendahuluan. Permasalahan berikutnya adalah perlunya peningkatan kapasitas dari pemuda-pemuda Desa Pakuan agar mampu mengelola tahura dengan baik.

Berdasarkan survei tersebut tim pelaksana berupaya untuk memaksimalkan fungsi tahura yang dapat dilakukan secara berkesinambungan dalam bentuk kegiatan pengabdian Universitas Mataram. Kerjasama antar fakultas tentunya akan sangat diperlukan sehingga permasalahan dapat diselesaikan secara paralel.

Karena fokus kegiatan ini adalah untuk memperluas akses internet, pada survei kedua, tim pelaksana menentukan posisi terbaik untuk meletakkan rangkaian penguat sinyal GSM agar dapat dimanfaatkan lebih maksimal.

\subsection{Pemasangan Perangkat Penguat}

Setelah kedua survei dilaksanakan, pemasangan rangkaian penguat GSM dilakukan pada tanggal 24 Oktober 2020 dengan melibatkan masyarakat di sekitarnya terutama untuk membantu mengangkat dan memasang tiang sebagai tempat meletakkan penguat sinyal GSM. Pemasangan penguat GSM ini merupakan salah satu solusi terhadap keterbatasan akses telekomunikasi di kawasan Tahura Nuraksa, terutama pada jalur menuju air terjun Segenter, seperti yang dijelaskan pada Bagian 1.

Gambar 2 menunjukkan bahwa sinyal yang dipancarkan oleh BTS terdekat yang berada di pintu masuk kawasan Tahura akan diterima oleh antena penerima. Antena penerima ini yang memancarkan sinyal tersebut ke segala arah (omni) dengan penguatan $60-70 \mathrm{Db}$.

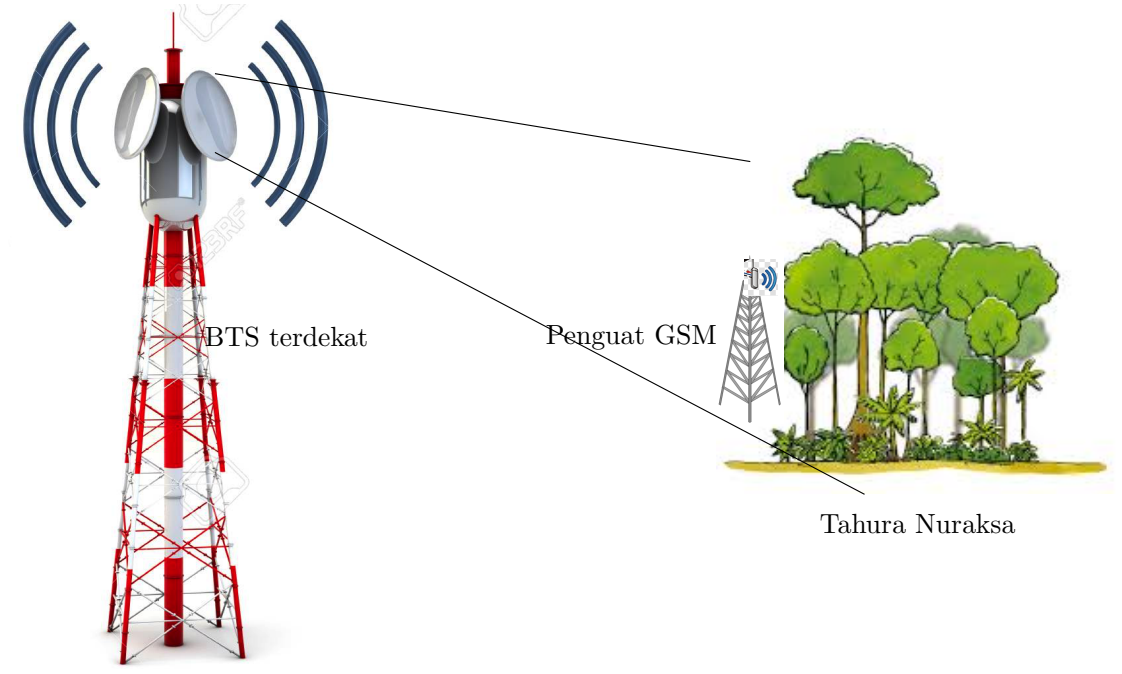

Gambar 2. Rancangan infrastuktur yang digunakan.

Setiba di lokasi, yang pertama dilakukan adalah memeriksa lokasi pemasangan penguat dan melakukan penggalian. Selanjutnya adalah merakit penguat dengan memasang beberapa perangkat seperti, rumah aki, rangkaian penerima dan pemancarnya, serta panel surya. Gambar 3 adalah proses merakit penguat yang akan dipasang. Gambar di sebelah kiri diambil ketika tim sedang mengatur pegangan panel surya sementara gambar di sebelah kanan diambil ketika tim sedang mengatur arah penguat dan posisi rumah aki. Ada sedikit kendala dalam pemasangannya karena diameter pegangan yang dipasang lebih kecil dari diameter tiang. Namun hal ini dapat diatasi dengan memasang pegangan besi berbentuk U untuk mengikatnya dengan tiang. Proses perakitan ini akhirnya dapat diselesaikan dalam 2 jam.

Proses pemasangan sendiri tidak terlalu lama karena lubang untuk memasang tiang telah dipersiapkan sebelumnya. Gambar 4 menunjukkan penguat GSM yang telah dipasang pada tiangnya dan telah berdiri di lokasi yang ditentukan. Gambar 5 adalah foto bersama tim pengabdian di depan penguat GSM yang telah dipasang.

Karena pemasangan penguat dilaksanakan pada hari Sabtu, maka penandatangan berita acara penguat GSM oleh Kepala Balai Tahura Nuraksa, Ibu Samsyiah Samad, S.Hut., M.Si., baru dilaksanakan pada hari kerja berikutnya yaitu tanggal 27 Oktober 2020. Gambar 6 menunjukkan foto perwakilan tim dengan Kepala Balai Tahura Nuraksa ketika menandatangai berita acara penyerahan alat. 

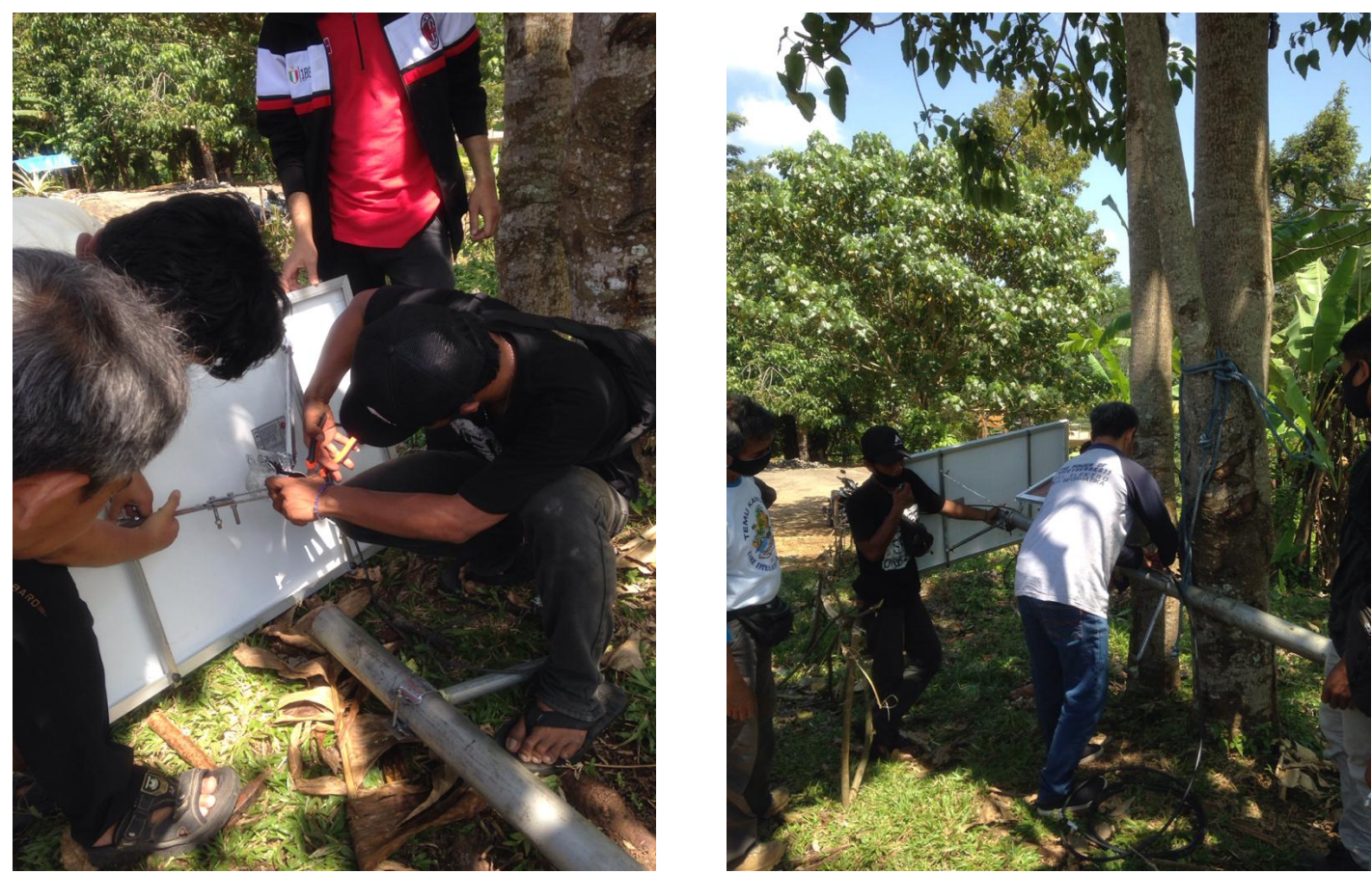

Gambar 3. Proses merakit penguat GSM.
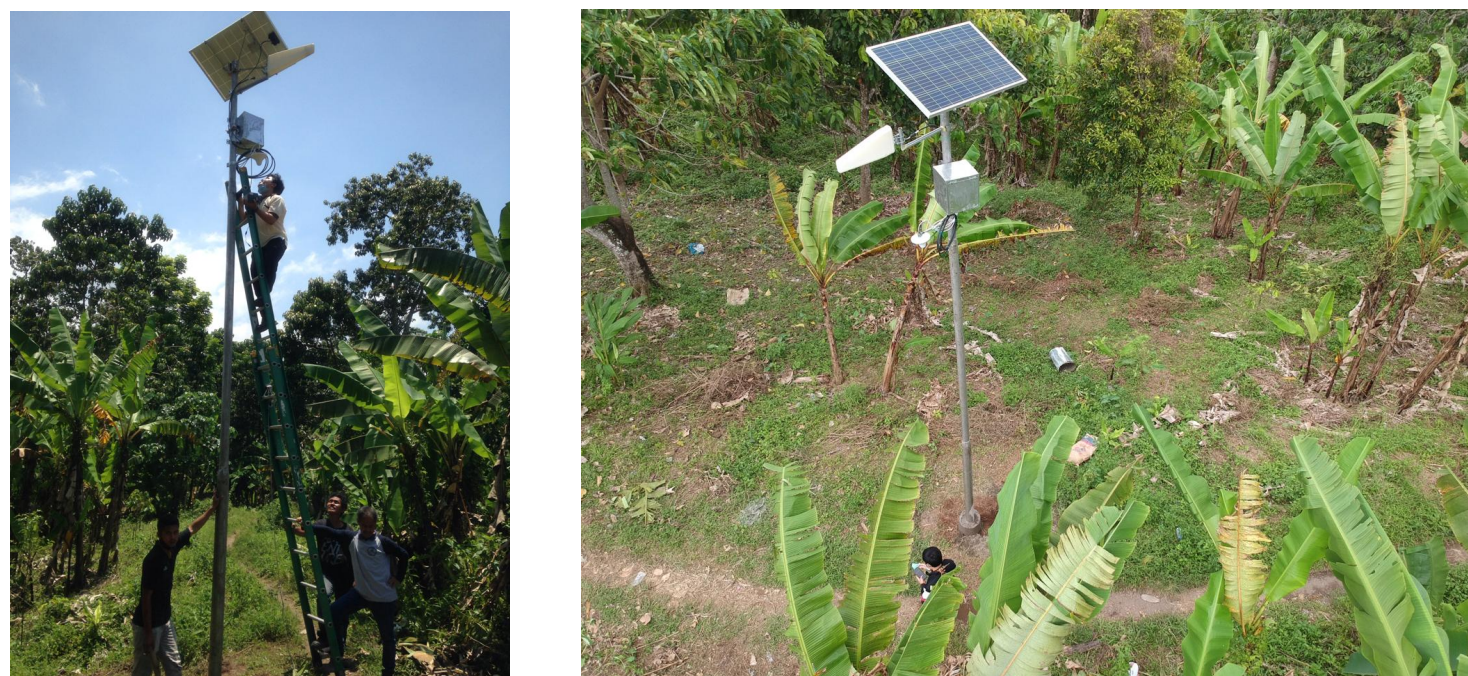

Gambar 4. Penguat GSM yang telah dipasang.

\section{HASil DAN Pembahasan}

Kunjungan untuk mengevaluasi peralatan dilakukan pada tanggal 5 Nopember 2020. Pada kunjungan tersebut, tim pelaksana berdiskusi dengan masyarakat yang berada di sekitar kawasan untuk mengetahui kekuatan sinyal pada kondisi cuaca yang berbeda-beda. Dari wawancara tersebut, diperoleh informasi bahwa alat berfungsi dengan baik sehingga komunikasi dapat di lakukan di daerah tersebut menggunakan saluran GSM. Namun, karena jarak dari BTS terdekat cukup jauh (sekitar $2 \mathrm{~km}$ ), tidak semua sinyal provider dapat diterima dengan baik. Untuk mengevaluasi kemampuan penguat, dilakukan pengamatan terhadap tiga kriteria yaitu telepon, chat, dan streaming. Untuk mewakili ketiga kebutuhan tersebut, tim pelaksana melakukan melakukan hubungan menggunakan telepon seluler dan aplikasi WhatsApp, serta mencoba aplikasi Youtube.

Tabel 1 menunjukkan sinyal dari provider-provider tertentu yang dapat ditangkap dengan baik oleh penguat 


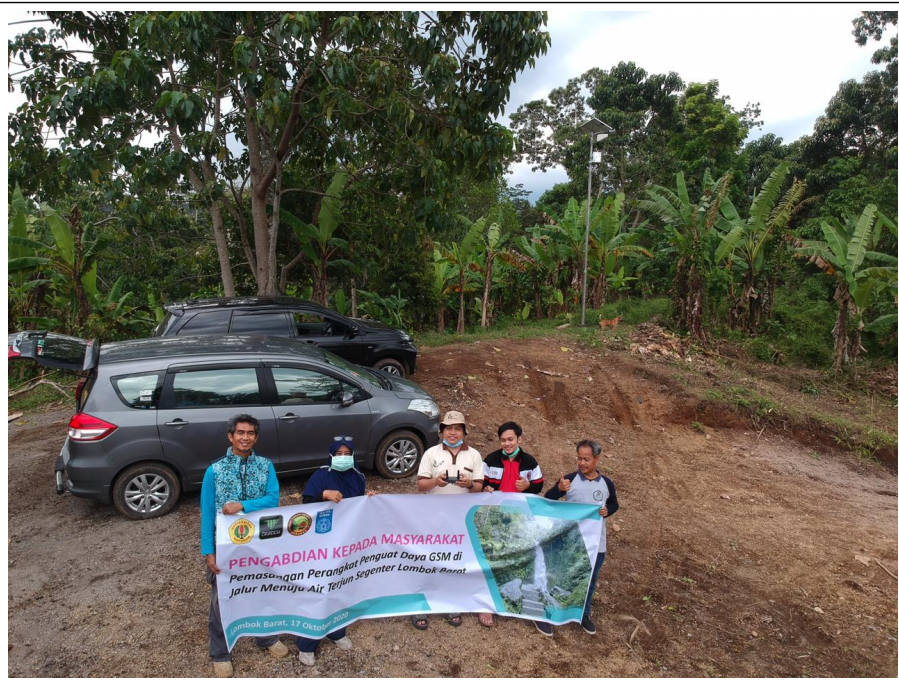

Gambar 5. Tim pengabdian di depan penguat yang telah dipasang.

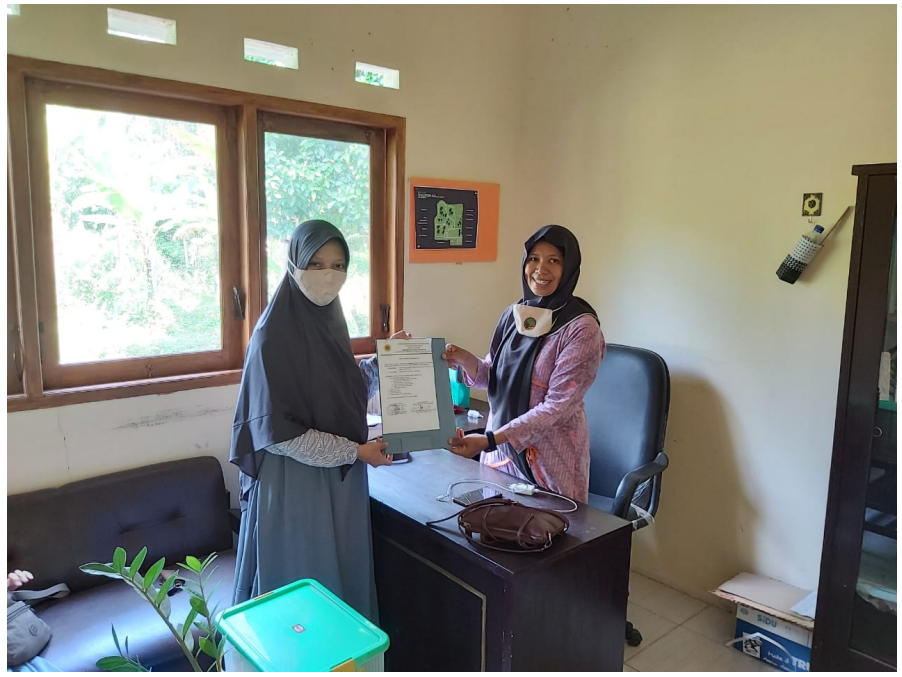

Gambar 6. Serah terima penguat GSM dengan Kepala Balai Tahura Nuraksa.

yang dipasang berdasarkan ketiga aplikasi tersebut. Selain provider, faktor lain yang mempengaruhi kekuatan sinyal adalah cuaca. Pada saat cuaca cerah, penguat dapat memancarkan sinyal secara maksimal sementara jika cuaca mendung, kekuatannya menurun. Kekuatan sinyal ini juga dipengaruhi oleh tenaga listrik yang disimpan oleh aki karena peralatan ini dijalankan menggunakan tenaga surya yang disimpan di sebuah aki secara otomatis.

Karena jarak dengan BTS terdekat yang cukup jauh, tim pelaksana menyarankan agar dibangun sebuah penguat lagi di antara BTS terdekat dengan penguat di Segenter. Selanjutnya perlu dilakukan pengamatanpengamatan untuk mengukur jarak area yang dapat dijangkau, kekuatan sumber energi, pengaruh cuaca, dan kemampuan baterai untuk menyimpan daya sehingga alat tersebut dapat memberikan unjuk kerja yang maksimal. Juga perlu dievaluasi apakah perlu pemasangan penguat di antara penguat tersebut dengan BTS jika penguat tersebut telah dioptimalkan.

\section{KeSimpUlan DAN SARAN}

Kegiatan ini telah berhasil mengistal perangkat penguat GSM di jalan menuju air terjun Segenter. Hasil evaluasi menunjukkan bahwa masyarakat dan wisatawan saat ini dapat mengakses sinyal GSM di area air 
TABEL 1. Sinyal YANG DAPAT DitANGKAP OLEH PENGUAT YANG DI PASANG.

\begin{tabular}{|c|c|c|c|}
\hline \multirow[t]{2}{*}{ Provider } & \multicolumn{3}{|c|}{ Kekuatan sinyal } \\
\hline & voice call & chat & streaming \\
\hline $\begin{array}{c}\text { Telkomsel } \\
\text { (dan By.U) }\end{array}$ & $\sqrt{ }$ & $\sqrt{ }$ & $?$ \\
\hline IM3 & $\checkmark$ & $\sqrt{ }$ & $\checkmark$ \\
\hline $\mathrm{XL}$ & $x$ & $x$ & $x$ \\
\hline $\begin{array}{l}\boldsymbol{J}: \text { kuat } \\
\boldsymbol{x}: \text { tidak ada } \\
\text { ?: tidak stab }\end{array}$ & & & \\
\hline
\end{tabular}

terjun Segenter sesuai dengan tujuan kegiatan ini. Selanjutnya untuk menyempurnakan unjuk kerja alat, dapat dilakukan analisa mengenai kekuatan baterai dan pengaruh cuaca terhadap daya pancar.

\section{UCAPAN TERIMA KASIH}

Terima kasih diucapkan kepada Program Studi Teknik Informatika yang telah mendukung pendanaan kegiatan ini dan alumni IKA-ITS cabang Nusa Tenggara yang telah membantu koordinasi dengan pihak Tahura Nuraksa.

\section{DAFTAR Pustaka}

[1] L. Hakim, "Implementasi Wajan Bolic pada Daerah Blankspot Desa Wisata Cibuntu-Kuningan," Format, vol. 6, no. 2, pp. 14-26, 2016.

[2] Y. N. Pratama, M. Ulum, and D. Rahmawati, "Rancang Bangun Antena Helix Sebagai Penguat Sinyal GSM Untuk Menunjang Komunikasi (Studi Kasus di Sekolah Darul Hadist Desa Klapayan Kabupaten Bangkalan)," SinarFe', vol. 2, no. 1, pp. 141-148, 2019.

[3] T. Nuraksa, "Peta Taman Hutan Raya," 12020.

[4] L. Onwuka, M. Okwori, S. Oladimeji, S. Oyewobi, C. Alenoghena, H. Bello Salau, S. Makusidi, and V. Asuquo, "Survey of Cellular Signal Booster," International Journal of Information Engineering and Electronic Business, vol. 10, pp. 21-31, 112018.

[5] S. O. Aliyu, L. Onwuka, and M. Okwori, "Development of a GSM Signal Booster for the 900 and 1800 MHz Bands using BA-ANN," in Conference: 2nd International Engineering Conference (IEC 2017) Federal University of Technology, Minna, Nigeria, 10 2017, pp. 426 - 436.

[6] B. Emin and S. Basbug, "Digital Repeater Design for Single Chip Radio Transceiver," in Conference: International Turkic World congress on Science and Engineering, 06 2019, pp. 791 - 799. 